\title{
PREDICTING CITIZEN SATISFACTION WITH THE QUALITY OF URBAN LIFE: A MATHEMATICAL MODEL FOR ASSISTING URBAN DECISION MAKERS
}

\author{
ROBIN N. WIDGer Y $\nmid$ HARRY K. EdWARdS $\ddagger$ and ANDrew S. BORCHERS $\$$ \\ †Department of Industrial Administration, General Motors Institute, 1700 West Third Avenue, \\ Flint, MI 48502. \\ †Department of Computer Science, University of Michigan-Flint, 1321 East Court Street, Flint, \\ MI 48503 and sVanderbilt University, Nashville. TN 37203, U.S.A.
}

\begin{abstract}
In the fall of 1977 and winter of 1978 , nearly 7000 citizens living in the Greater Flint Area (Michgan, U.S.A.), were interviewed in depth to assess the community's quality of life. This survey was sponsored by The Charles Stewart Mott Foundation for the purpose of developing an information system usable to grassroots and community-wide decision-making groups. The data were analyzed for each of 42 neighborhoods, as well as for the total area.

The purpose of this paper is to explain a predictive model developed by using multiple linear regression techniques. Thirty-eight factors were regressed against two dependent variables:

(1) Citizen satisfaction with the quality of life in the Flint area.

(2) Citizen satisfaction with the quality of life in the neighborhood

The 38 independent factors used in the modeling represented various social and psychological aspects of community life. It is believed that a knowledge of how these human dimensions contribute to citizens satisfaction with the quality of community life will sensitize leaders to the likely outcomes of their community development policies.
\end{abstract}

\section{INTRODUCTION}

SAVING American cities is a presumptuous task. Yet this is exactly what the authors believe is required of our country's leaders and best minds during the next 10 years. In order to save or restore any kind of major human system, decision and policy makers need appropriate and reliable information about conditions within the system. They also need to possess an awareness of the relationship existing among the multitude of components constituting that system. Relative to American cities today, neither adequate data nor knowledge of relationship exists. What is needed is a general systems model which explains the economic, political, social, psychological and environmental factors that make cities what they are.

This is a tremendously tall order, but one that should gain support from every student of urban systems. The scope of this study was not to tackle the whole challenge laid out above. The purpose was to explore a little-studied but extremely important aspect of an urban system-the modeling of the social psychology of city living. More specifically the authors' purpose was to explore the degree to which people living in one community (Flint, Michigan, U.S.A.) experience "satisfaction with the quality of life" in their neighborhoods and in the city in general. Moreover, the specific objective was to explore, via mathematical modeling techniques, the major social and psychological predictors of citizen satisfaction with the quality of life

These predictors should provide policy and decision makers in the City of Flint the information they need to allocate resources in ways that may have payoffs in higher citizen satisfaction with city and neighborhood life. As satisfaction improves, further payoffs should be realized in higher levels of citizen involvement in community improvement activity and in lower levels of citizen desire to move away from Flint.

\section{METHOD OF RESEARCH}

During the fall of 1977 and winter of 1978,6917 adults were selected at random for in-depth interviews. Most of these interviews were conducted by telephone, lasting an 
average of $45 \mathrm{~min}$. About 250 interviews were conducted in-home in those neighborhoods having a relatively high percentage of residents without phones. In the City of Flint, 3719 interviews were conducted - approximately 100 from each of 37 defined neighborhoods. These city interviews provided the data base for the analysis presented in this paper.

\section{Questionnaire}

There were more than 200 items in the questionnaire. These were designed to measure several important social and psychological dimensions of community life. These included:

(1) Citizen Satisfaction with 57 aspects of community life.

(2) Degree of Citizen Knowledge of the community.

(3) Optimism about the future of the neighborhood and community at large.

(4) Perceived Power of citizens to influence community institutions.

(5) Citizen Motivation (desire) to help solve neighborhood problems.

(6) Citizen Commitment to the community (strength of desire to stay in the Flint area).

(7) Degree of Citizen Activity in the neighborhood and in the community at large.

(8) Degree of Citizen Affiliation and Membership in local organizations.

(9) Amount of Citizen Support for various civic institutions.

(10) Amount of Citizen Trust and Confidence in community institutions.

(11) Citizen Opinions regarding life in the neighborhood and community at large.

(12) Identification of Neighborhood and Community-Wide Problems.

(13) Demographic Data - e.g. sex, age, race, income.

\section{Model for data handling}

The data handling work flow followed the structure shown in Fig. 1.

Step one. This involved preparing a descriptive analysis, a report to the community on each of the dimensions listed above. The report is called The Flint Area Neighborhood Quality of Life Report, (known more commonly as 'The Flint Process'). The data were reported for 42 neighborhood areas -37 in Flint and 5 outside the city itself.

Step two. This phase involved factor analyzing the more than 200 questionnaire items to define the underlying factor structures. In all, 40 factors were identified (see Table 1). Twenty-two of these are various satisfaction scores. Three are for 'trust' in various institutions serving the community-government/political, business, and information (media). Other factors defined various citizen opinions and behaviors.

Step three. In this phase, multiple linear regression analyses (step-wise program) were employed using two dependent variables: (1) overall satisfaction with the quality of life in the neighborhood, and (2) overall satisfaction with the quality of life in the Flint area. All 38 other factors were regressed as independent variables. Each individual sample score for each factor was transformed for the regression analysis by multiplying it by the score's loading within the factors - thereby representing its weighting within the factor. In addition to using multiple linear regression analyses for the total city sample, analyses were made by race and by age.

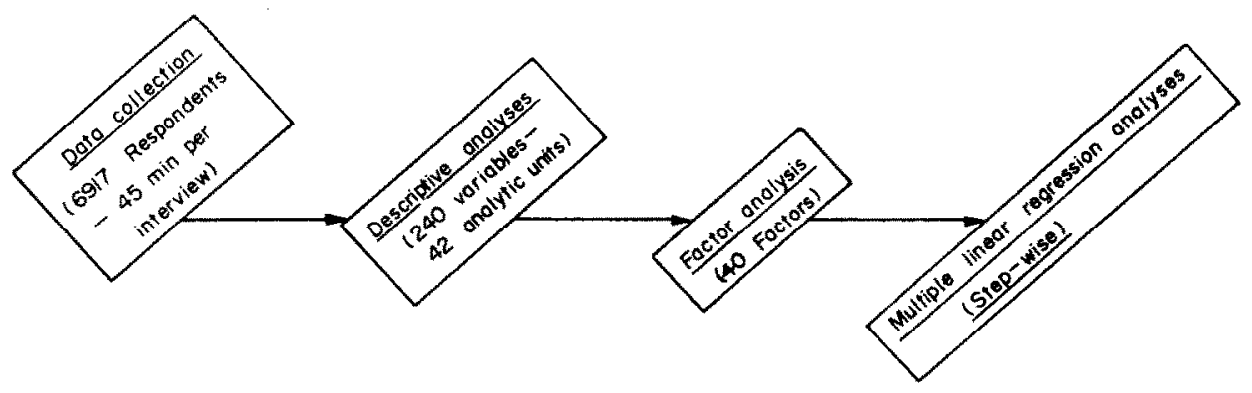

Fig. 1. Data handling work flow. 
Table 1. Factors defined by factor analysis

\begin{tabular}{lll}
\hline \multicolumn{1}{c}{ Trust } & \multicolumn{1}{c}{ Satisfaction } & \multicolumn{1}{c}{ Opinions } \\
Government and political system & Aesthetics & Optimism \\
Business system & Communication systems & Potency \\
Information system & Recreation and entertainment & Support \\
\multicolumn{1}{c}{ Demographics } & Neighbors & Desire to move \\
Dwelling & Sense of security & Behavior \\
Longevity & Economic conditions & Affiliation/Membership \\
Income level & Government and community leadership & Activity \\
Shift & Home & Motivation \\
Number of children & Family/Friends & \\
Race & Government and community services & \\
Sex & Educational system & \\
Employment status & Climate & \\
& Race relations & \\
& Trees & \\
& Employment & \\
& Transportation & \\
& Safety services & \\
& Traffic and streets & \\
& Hospitals & \\
& Medical services & \\
& $* *$ Neighborhood & \\
& $* *$ Flint area & \\
\hline
\end{tabular}

** Indicates major dependent variables.

\section{RESULTS}

The two critical dependent variables in this study are overall citizen satisfaction with the quality of life in (1) the Flint area and (2) the neighborhood. In Tables 2 and 3, the best predictors of the dependent variables resulting from the multiple linear regression analyses are displayed. All reported predictor variables are significant at the 0.05 levelusing the critical value of $t$ as the determinant.

\section{Predictors of satisfaction with the Flint area}

Using the proportion of variance accounted for $\left(R^{2}\right), 5$ independent variables are the most important predictors of satisfaction with the Flint area: "Trust in Government and Political System", satisfaction with "Family and Friends", 'Aesthetics' (Attractiveness), "Age and Years in the Community", and "Degree of Optimism". Less important (but statistically significant) predictors are satisfaction with "Climate", "Race Relations", and "Degree of Affiliation and Membership" (see Table 2).

$B y$ race. Some interesting differences emerge when Blacks and Whites are analyzed separately. While the highest predictor of community-wide satisfaction for Blacks is "Trust in Local Government and Political System", the best predictor for Whites is satisfaction with "Local Government and Leadership". Neither of these variables is a significant predictor for the other group. Moreover, "Trust in the Business System" is important among Whites, but not among Blacks. While satisfaction with "Neighbors" and "Race Relations" are significant for Whites, "Satisfaction with Home" and "Degree of Affiliation and Membership" are important among Blacks.

$B y$ age. Young adults differ from older citizens in that "Satisfaction with Race Relations" and "Trust in Local Government and Political System" are not important predictors of overall satisfaction with city life. Unlike the older groups "Trust in Business" and "Satisfaction with Employment" are important predictors among the young. The middle and older groups differ in that satisfaction with "Educational System" is important for the middle aged and satisfaction with the "Communication System" is a significant predictor for the older group. "Satisfaction with Aesthetics" is not a predictor for older citizens, but it is important to both the young and middle aged.

\section{Predictors of satisfaction with neighborhoods}

When examining the total city sample, 5 significant independent variables emerge as 


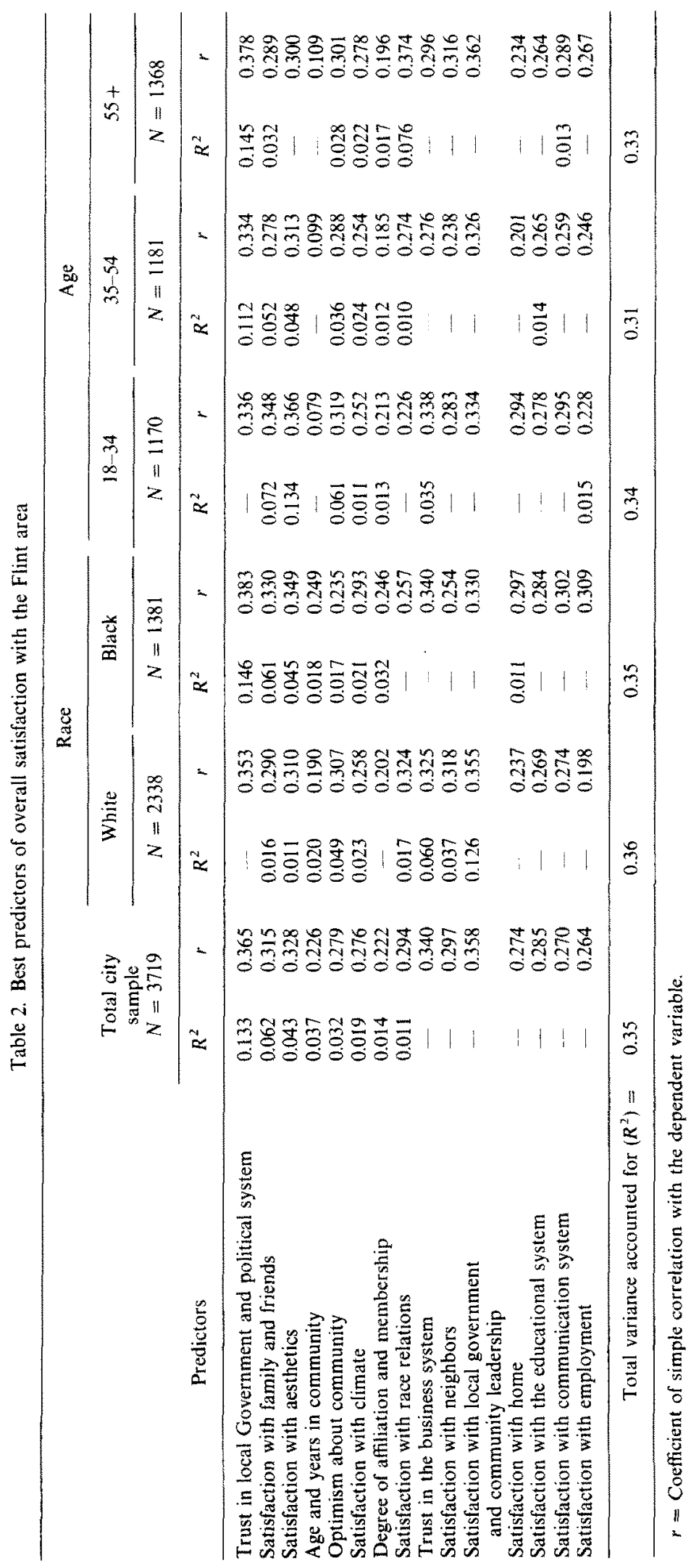




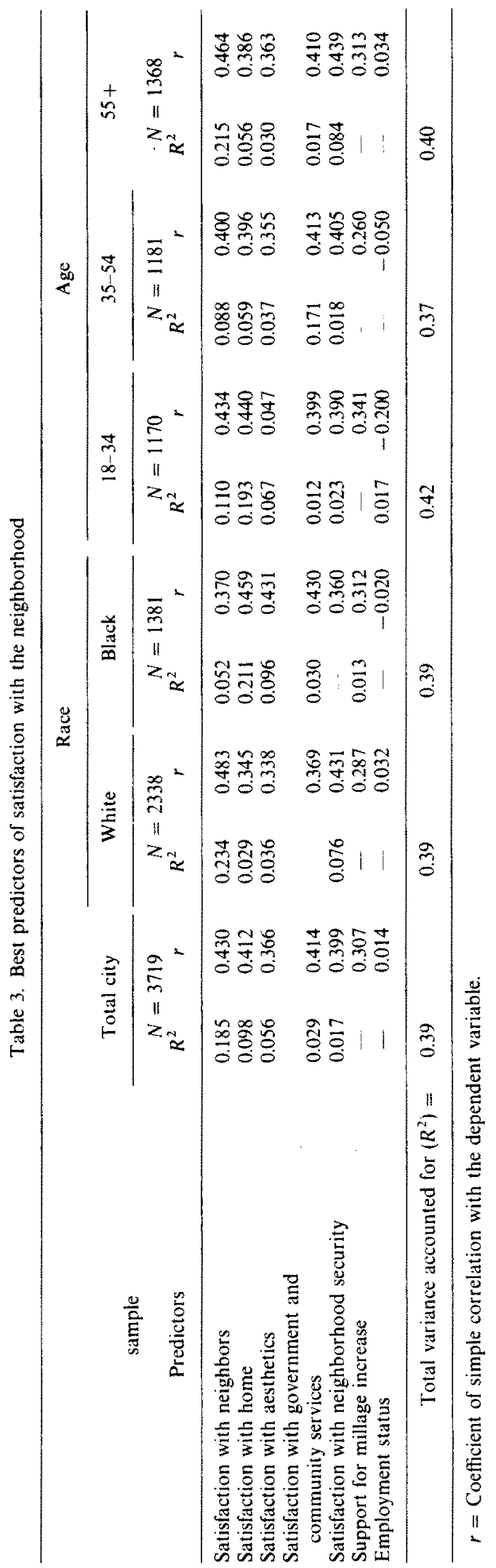


significant predictors of satisfaction with neighborhood: satisfaction with "Neighbors", "Home", "Aesthetics", "Government and Community Services" and "Neighborhood Security". These 5 account for nearly $40 \%$ of the total variance (see Table 3 ).

By race. The most obvious difference between Black and White predictors is the magnitude of $R^{2}$ for the lead predictor for each group. High for Whites is satisfaction with "Neighbors" $(0.234)$; high for Blacks is satisfaction with "Home", (0.211). A more important predictor for Whites is "Satisfaction with Neighborhood Security", while to Blacks "Satisfaction with Government and Community Services" is more important. Moreover, there is a significant relationship between neighborhood satisfaction and "Support for Millage Increases" among Blacks.

$B y$ age. It is interesting to note in Table 3 the difference in the leading predictor for each of the 3 age groups: "Home" for the young (0.193), "Government and Community Services" for the middle group (0.171), and "Neighbors" for the older citizens $(0.215)$. Among the younger groups "Employment Status" is significant. Finally, it is also interesting to note the higher $R^{2}(0.084)$ for "Neighborhood Security" among older citizens than for the young and middle aged.

\section{DISCUSSION}

When doing correlational research such as that described above, it is essential to remind the reader that while causality between independent (predictor) variables and dependent variables may be 'assumed', causality is not proven nor even supported scientifically. However, assumptions of causality may be made by the researcher when testing theory using correlational techniques. In this case of providing policy makers with correlational data (predictors of various dependent variables as is the purpose here), the data should be interpreted as suggestive of types of relationships-some probably causal, some coincidental and some neither.

Of some concern to the researchers was the relatively low total variance accounted for $\left(R^{2}\right)$ in the multiple linear regression analyses: 0.35 for "overall satisfaction with the Flint area", and 0.39 for "satisfaction with the neighborhood". To gain a better understanding of why this occurred, scatter plots were run for both dependent factors against each independent factor. Several scatters indicated significant curvilinear relationships existing between dependent and independent factors. Since multiple regression analysis assumes linearity among factors, it is likely that much unaccounted for variance is hidden in non-linear relationships. Moreover, it is reasonable to assume that there were many variables that were not measured in the survey that could account for more of the variance of the two dependent factors.

\section{CONCLUSION}

Providing usable information to urban policy and decision makers has been the center of concern to the authors. A far greater problem is to insure that such information is presented in a simplified format and then used. Too often, however, local politicians make decisions based on philosophy, campaign promises, or reactions to the most vocal or strongest pressure group - without sufficient study of the most pertinent information on the issue.

In this paper, the authors have developed a mathematical model, using multiple linear regression techniques, to show urban planners and decision makers one way to better understand the relationships existing between citizen satisfaction with the community and several other psychological and social dimensions. Although it is difficult to encourage urban decision makers to decide policy, based on coefficients or other indicators of relationship, it is hoped that they will learn to use such data in order to gain a better intuitive grasp of the dynamics of the human experience in the community. Such usage should heighten their sensitivity to the constituency, and it should give them a better feeling for the likely outcomes resulting from their decisions. 